\title{
Application of Ionic Liquids in the Downstream Processing of Lignocellulosic Biomass
}

\author{
Sviatlana Siankevicha, Zhaofu Fei ${ }^{a}$, Ning Yan ${ }^{\star b}$, and Paul J. Dyson ${ }^{\star_{a}}$
}

\begin{abstract}
Chemical transformations of lignocellulosic substrates to valuable platform chemicals are challenging as lignin and cellulose have high thermal and chemical stabilities. However, certain ionic liquids are able to dissolve and deconstruct biomass and, in the presence of catalysts, convert the dissolved/deconstructed species into useful platform chemicals. Herein, we provide a concise overview of the role of ionic liquids in biomass processing. Using 5-hydroxymethylfurfural as an example of a renewable building block, available from cellulose, we show how ionic liquids can facilitate its production.
\end{abstract}

Keywords: Biomass · Ionic liquids · Renewable feedstocks · Sustainable chemistry

\section{Introduction}

It has been estimated that more than 40 million tons of inedible plant material, including wheat stems, corn stover (the stalks and leaves) and wood shavings from logging, are produced annually, and are not valorized. ${ }^{[1]}$ This vast quantity of inedible lignocellulosic feedstock (Fig. 1) contains an abundance of valuable chemicals and currently extensive investigations are in progress to find viable ways to convert this waste material. ${ }^{[2]}$ The transformation of lignocellulosic biomass into commodity chemicals is of growing importance as alternative feedstocks to petrochemical derived compounds. ${ }^{[2 a, b, d, 3]}$ As a renewable feedstock, constructed largely from $\mathrm{CO}_{2}$, the valorization of waste biomass will help to reduce dependence on fossilbased resources, the latter of which leads to increased $\mathrm{CO}_{2}$ levels in the atmosphere and, hence, climate change. ${ }^{[4]}$ As such, energy efficient routes must be used for the processing and transformations of lignocellulosic biomass. In this respect, ionic liquids could offer advantageous features over other solvents and processing methods, as they can facilitate the dissolution of biopolymers and simultaneously catalyze their transformation into key chemical intermediates.

${ }^{\star}$ Correspondence: Dr. N. Yan ${ }^{\text {b }}$ Prof. P. J. Dyson ${ }^{a}$ anstitut des Sciences et Ingénierie Chimiques Ecole Polytechnique Fédérale de Lausanne (EPFL)

$\mathrm{CH}-1015$ Lausanne, Switzerland

${ }^{\mathrm{b}}$ Department of Chemical and Biomolecular

Engineering

National University of Singapore

4 Engineering Drive 4, 117576, Singapore

E-mail: ning.yan@nus.edu.sg; paul.dyson@epfl.ch

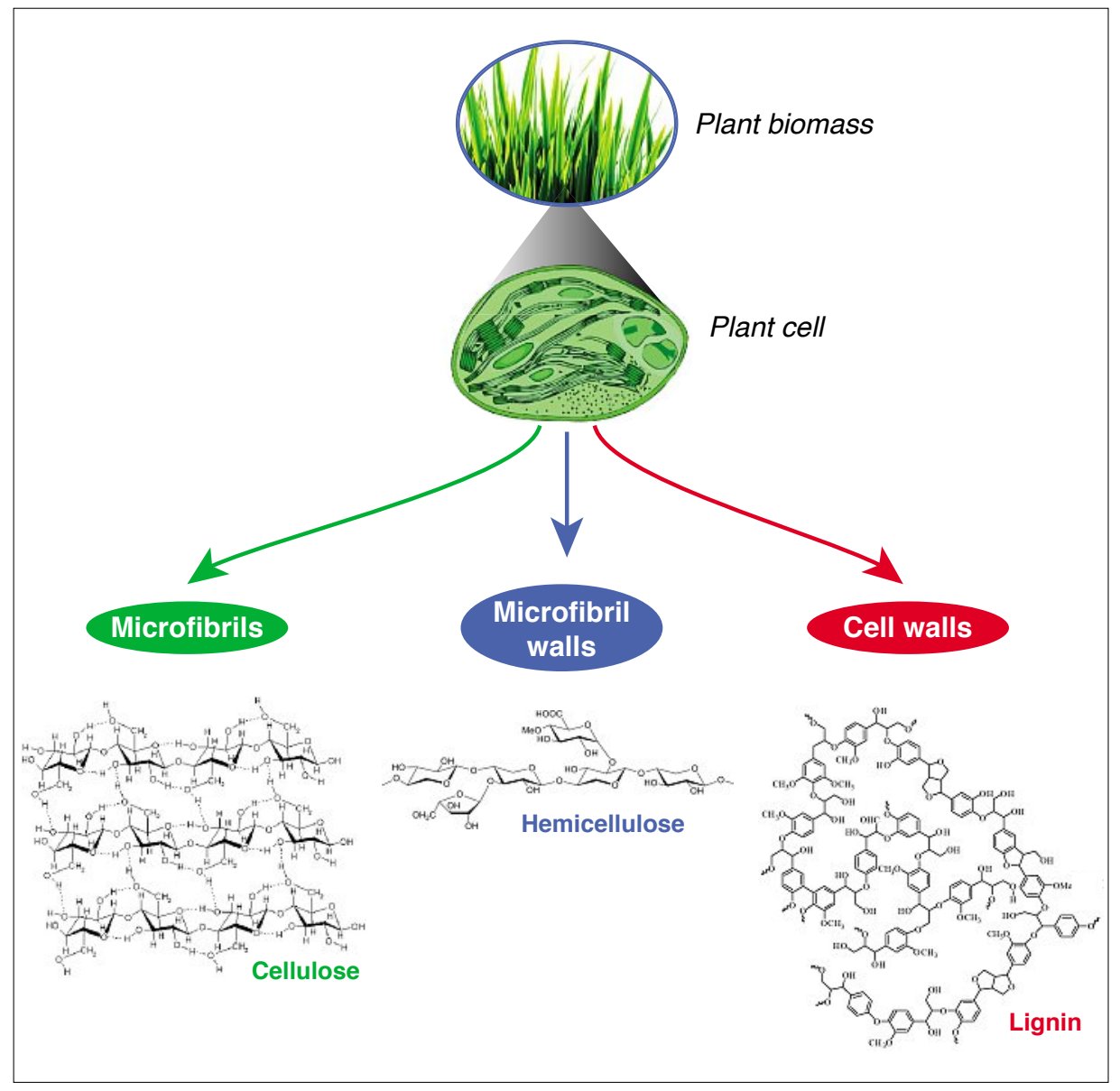

Fig. 1. Composition of lignocellulosic biomass.

\section{Solubilizing Cellulose}

A wide and diverse variety of chemicals may be obtained from biomass and many different chemical products and processes are under development. In the majority of cases, the lignocellulosic material must first be fragmented into its constitu- ent parts so that it can be efficiently transformed via specific refining strategies. Plant biomass is composed of three main components, cellulose (40-50\%), hemicellulose (25-35\%) and lignin (15-20\%), which require pretreatment in order to breakdown its rigid structure and separate the cellulose from lignin. ${ }^{[5]}$ 
The strong hydrogen bonding network in cellulose leads to significant thermal and chemical stability, which hinders dissolution. Transformation of cellulose into valuable products under moderate conditions is also very challenging. Several routes have been reported that convert cellulose into sugar monomers. Notably, only a limited number of solvent systems have been found to work, including $\mathrm{LiCl} / \mathrm{N}, \mathrm{N}$-dimethylacetamide, ${ }^{[6]}$ LiCl/N-methyl-2-pyrrolidine, ${ }^{[7]}$ LiCl/1,3-dimethyl-2-imidazolidinone, ${ }^{[8]}$ dimethylsufoxide/paraformaldehyde, ${ }^{[9]}$ $N$-methylmorpholine- $N$-oxide, ${ }^{[10]}$ molten salt hydrates such as $\mathrm{LiClO}_{4} \cdot 3 \mathrm{H}_{2} \mathrm{O}$ and LiSCN $2 \mathrm{H}_{2} \mathrm{O},{ }^{[11]}$ and some aqueous solutions containing metal complexes. ${ }^{[12]}$ However, these solvents have some limitations such as volatility, toxicity, recovery problems, or instability. Among the solvents mentioned above, none are currently used to produce sugar monomers from cellulose on an industrial scale, although $\mathrm{N}$-methylmorpholine- $\mathrm{N}$-oxide and water is used to manufacture regenerated cellulose fibers and films. ${ }^{[13]}$ Nevertheless, the use of the $N$-methylmorpholine- $N$-oxide/water system is associated with some problems, such as the high temperatures required to dissolve and degrade the cellulose leading to solvent decomposition and high operating costs. A promising alternative to the solvent systems mentioned above comprises the use of aqueous solutions of $\mathrm{NaOH} /$ urea, $\mathrm{NaOH} /$ thiourea and $\mathrm{LiOH} /$ urea that dissolve cellulose at relatively low temperatures. ${ }^{[14]}$ Another promising approach is based on an inexpensive $\gamma$-valerolactone/ water $/ \mathrm{H}_{2} \mathrm{SO}_{4}$ system that dissolves biomass, including the lignin fraction. ${ }^{[15]}$ Interestingly, $\gamma$-valerolactone can be obtained by the catalytic hydrogenation of levulinic acid which itself is accessible from the hydrolysis of lignocellulosic bio-

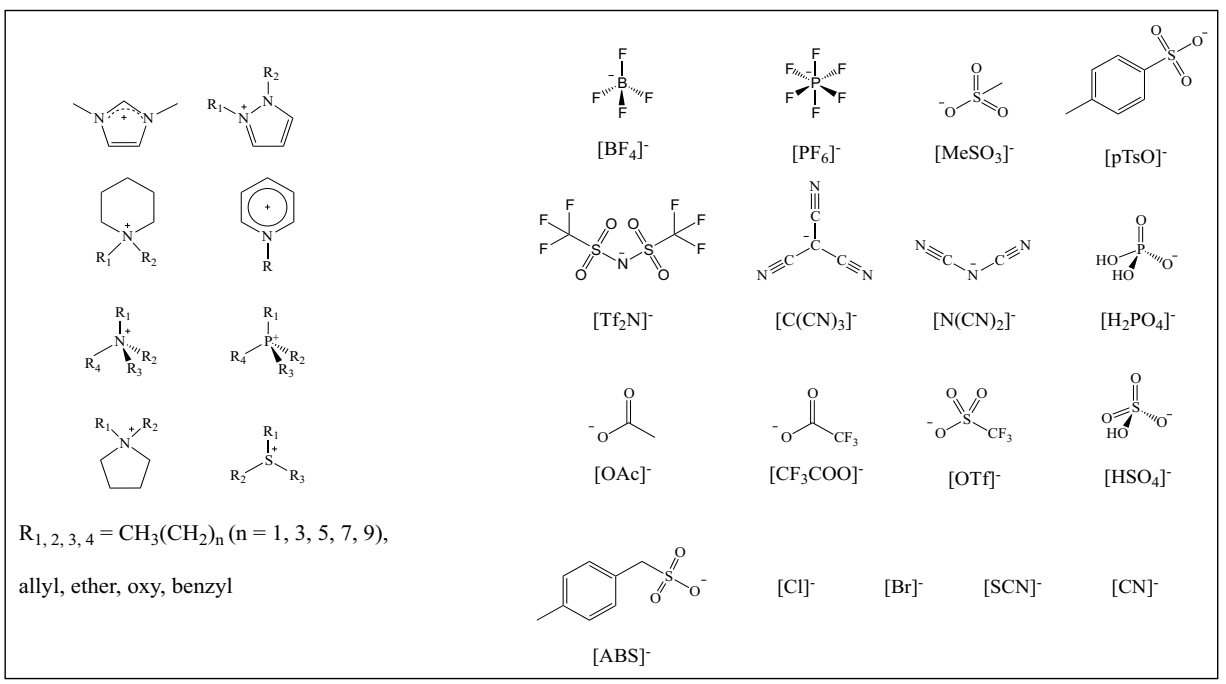

Fig. 2. Examples of ionic liquid cations and anions that have been evaluated in biomass processing. mass, ${ }^{[16]}$ making this system particularly attractive. Supercritical $\mathrm{CO}_{2}$ may also be

In addition to the solvent systems described above, the pretreatment of biomass using ionic liquids shows considerable potential, due to their efficiency in breaking down biomass and their comparatively benign nature (see Fig. 2). Ionic liquids are often referred to as green solvents, essentially as they are non-volatile and therefore can be easily contained and reused. ${ }^{[18]}$ Ionic liquids are also endowed with unique properties, able to dissolve and activate substrates in various transformations, ${ }^{[18 b]}$ potentially overcoming some technological barriers which allow renewable resources or waste materials to be used more efficiently. ${ }^{[19]}$ Moreover, ionic liquids may be derived from lignocellulosic materials themselves ${ }^{[20]}$ and ionic liquids can be functionalized/tuned in a rational way to improve their properties for a specific application. [21]

The first report describing the dissolution of cellulose in an ionic liquid dates back to a US patent filed in 1934. ${ }^{[22]}$ The ionic liquid disclosed in the patent, i.e. $[\mathrm{N}$-ethylpyridinium $] \mathrm{Cl}$, operates in the presence of organic bases. However, this system has a relatively high melting point and, at that time, was considered to be of little practical value. ${ }^{[23]}$ In 2002 Rogers and coworkers showed that cellulose could be dissolved in 1-butyl-3-ethylimidazolium chloride, $[\mathrm{bmim}] \mathrm{Cl}$, in concentrations up to $25 \mathrm{wt} \%{ }^{[24]}$ These results led to a renascence in the field, opening up viable ways to process cellulose and initiating extensive research in the area. The ability of ionic liquids to dissolve cellulose depends on the nature of the native cellulose (its degree of polymerization and its crystallinity), on the operating conditions (temperature, reaction time, initial used for biomass hydrolysis. ${ }^{[17]}$ concentration of cellulose in the ionic liquid, activation with microwaves, etc.), the presence of impurities, ${ }^{[25]}$ and of course, on the nature of the ionic liquid. It has been shown that the extensive hydrogen bonding in the cellulose structure is effectively disrupted by the [bmim] $\mathrm{Cl}$ ionic liquid, with the formation of hydrogen bonds between the chloride anion of the ionic liquid and the hydroxyl groups of the polysaccharides, with further $\mathrm{H}$-bonding interactions involving the acidic protons of the imidazolium cation. ${ }^{[26]}$ Furthermore, ion dipoletype interactions between cation and anion of the ionic liquid stabilize the disrupted chains, impeding re-crystallization of the biopolymer. ${ }^{[27]}$ It has also been shown that lignin dissolves in some ionic liquids. ${ }^{[28]}$ Since many catalysts also dissolve/disperse in ionic liquids ${ }^{[18 a, 29]}$ the ability to dissolve both cellulose and lignin opens up many options for their transformation into platform chemicals, some of which are described below.

Mechanistic studies indicate that the nature of the ionic liquid anion is critical, contributing to the formation of H-bonds as mentioned above for the chloride anion, but extending to other anions such as $[\mathrm{OAc}]^{-}$and $\left[\mathrm{HCO}_{2}\right]^{-}$which have a good H-bond basicity, ${ }^{[25]}$ whereas weakly basic anions such as $\left[\mathrm{N}(\mathrm{CN})_{2}\right]^{-}$and $\left[\mathrm{CH}_{3} \mathrm{CHOHCO}_{2}\right]^{-}$are less effective for cellulose dissolution. ${ }^{[30]}$ Ionic liquids containing non-coordinating anions such as $\left[\mathrm{BF}_{4}\right]^{-}$ and $\left[\mathrm{PF}_{6}\right]^{-}$are also unable to efficiently dissolve cellulose. ${ }^{[31]}$ As the size of the anion in an ionic liquid increases, its ability to form $\mathrm{H}$-bonds tends to decrease, which reduces the ability of the ionic liquid to dissolve cellulose. ${ }^{[25]}$ Based on the influence of anion to dissolve cellulose as a function of the H-bond basicity and multiple (secondary) hydrogen donating profiles, which combined lead to the disruption of inter- and intra-molecular $\mathrm{H}$-bonds in cellulose, the following sequence has been proposed for cellulose solubility: $[\mathrm{OAc}]^{-}$ $>\left[\mathrm{HSCH}_{2} \mathrm{CO}_{2}\right]^{-}>\left[\mathrm{HCO}_{2}\right]^{-}>\left[\left(\mathrm{C}_{6} \mathrm{H}_{5}\right)\right.$ $\left.\mathrm{CO}_{2}\right]^{-}>\left[\mathrm{H}_{2} \mathrm{NCH}_{2} \mathrm{CO}_{2}\right]^{-}>\left[\mathrm{HOCH}_{2} \mathrm{CO}_{2}\right]^{-}>$ $\left[\mathrm{CH}_{3} \mathrm{CHOHCO}_{2}\right]^{-}>\left[\mathrm{N}(\mathrm{CN})_{2}\right]^{-} \cdot[28,30 \mathrm{~b}, 31]$

Although the role of the ionic liquid anion is dominant, the nature of the cation is also influential and the size and functional groups attached to the cation play a significant role on the solubility of cellulose. ${ }^{[32]}$ Various cations have been evaluated for their ability to enhance the dispersion and dissolution of lignocellulosic biomass including choline, imidazolium, pyrrolidinium, pyridinium, ammonium and phosphonium cations (see Fig. 2). ${ }^{[25,33]}$ In general, planar, heterocyclic cations such as the pyridinium and imidazolium cations are most efficient at deconstructing cellulose, $[32 \mathrm{~b}, 33 \mathrm{c}]$ presumably as they can insert into the biopolymer structure and form H-bonds. The 
inclusion of specific functionalities, covalently bound to the cation, further promote the solvation of cellulose with allyl, ${ }^{[34]}$ $-\mathrm{CN},{ }^{[35]}-\mathrm{OH},{ }^{[33 \mathrm{c}]}-\mathrm{SO}_{3} \mathrm{H}^{[36]}$ groups all having beneficial effects. While many different substituents/functional groups can be envisaged that may enhance the dissolution of biomass it has been shown that, in the case of cellulose and in the absence of overriding electronic effects, smaller side chains are optimum. ${ }^{[32 a, 37]}$

\section{Cellulose Transformations into Furans}

A wide range of chemical approaches can be considered for valorizing cellulose and lignocellulose as raw materials for the production of chemicals that complement or compete with biotransformations. In the presence of suitable catalysts, such as transition metal nanoparticles, biomass may be transformed in aqueous solutions in the presence of hydrogen and/or other additives into a number of valuable small molecules. ${ }^{[38]}$ In this context, the conversion of various cellulosic derivatives to 5-hydroxymethylfurfural (HMF), one of the principal pathways defined in the field (as HMF may subsequently be transformed into other compounds), has been extensively studied in ionic liquids (Fig. 3). ${ }^{[3 a, 39]}$

Imidazolium chloride ionic liquids combined with transition metal catalysts have an exceptionally high capacity for efficient production of HMF via hydrolysis of polysaccharides into monosaccharides and dehydration of the latter. ${ }^{[40]}$ Different mechanistic routes have been proposed for the transformation of glucose involve two main steps, first ring opening and, second, proton transfer between $\mathrm{C} 1$ and C2 (Scheme 1). From fructose there are two possible pathways relating to HMF to fructose, ${ }^{[3 a, 39 a]}$ although all essentially

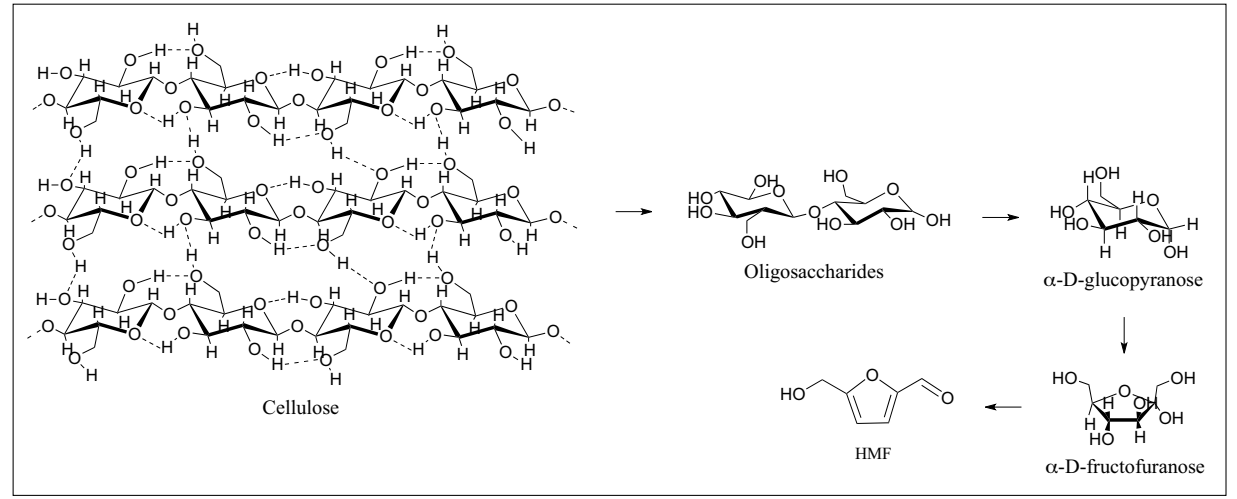

Fig. 3. Stepwise transformation of cellulose into HMF (the entire process can be achieved in a single step in ionic liquids).

formation, involving either the dehydration of fructose by an open-chain pathway via two 1,2-eliminations and one 1,4-elimination of water or a pathway involving a cyclic fructofuranosyl intermediate. ${ }^{[41]}$

The highest yields are obtained using chromium(II) chloride as the pre-catalyst ${ }^{[3 \mathrm{a}]}$ in 1-ethyl-3-methylimidazolium chloride, [emim] $\mathrm{Cl}^{[42]}$ We have shown, in recent years, that carefully designed ionic liquids can facilitate catalyzed reactions due to the formation of specific interactions between the substrate, intermediate, and products. For example, nitroarenes, ${ }^{[43]}$ aryl halides $^{[44]}$ and phenolic ${ }^{[45]}$ compounds can be activated by the formation of $\mathrm{H}$-bonds with appropriate substituents on the ionic liquid cation. The strength of the interactions between the cations and anions in the ionic liquid are also critical - ideally they should form preferential interaction with the substrate rather than each other. Moreover, functional groups attached to an ionic liquid cation may also stabilize a catalyst leading to improved overall performance. ${ }^{[46]}$ Consequently, we have applied these concepts to the conversion of carbohydrates into HMF to show that hydroxyl-functionalized and hydroxyl-

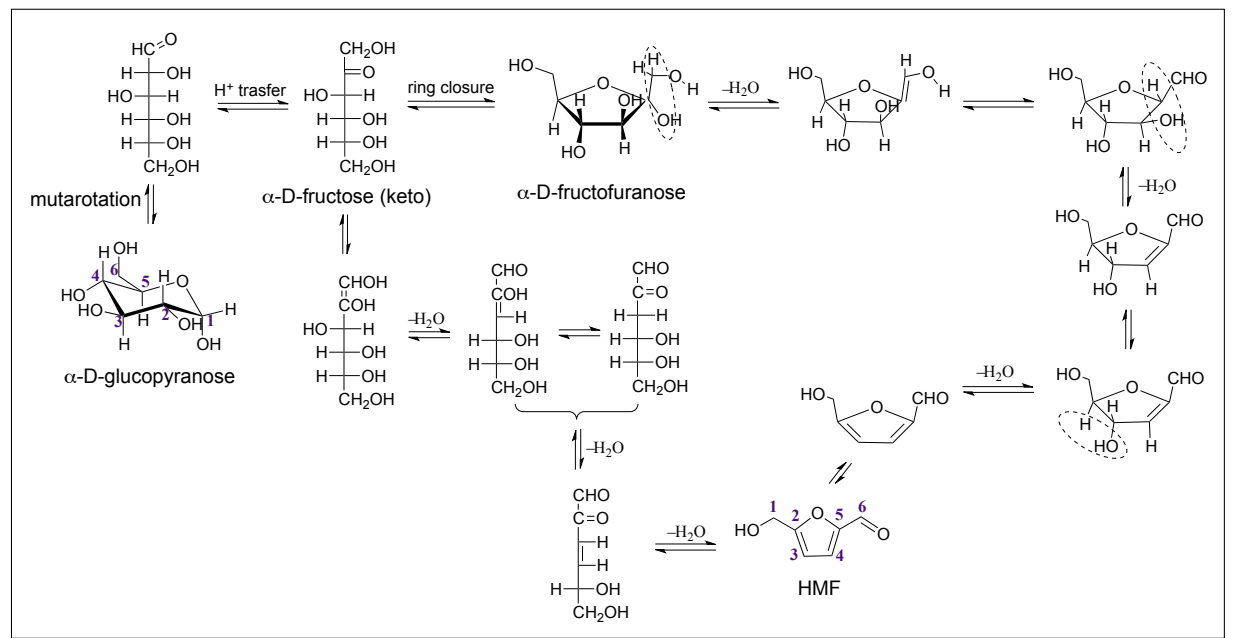

Scheme 1. Reaction pathways for dehydration of glucose into fructose followed by HMF formation through an open-chain pathway ${ }^{[41 \mathrm{~d}]}$ and a pathway involving a cyclic fructofuranosyl intermediate. ${ }^{[41 \mathrm{e}]}$ phenyl-functionalized imidazolium-based ionic liquids (Fig. 4) result in considerably higher yields of HMF compared to simple imidazolium chloride systems. ${ }^{[47]}$

Based on spectroscopic and computational studies we have tentatively inferred that the hydroxyl group on the cation forms a strong hydrogen bond with the $\mathrm{OH}$ group of glucose, thereby weakening and activating the $\mathrm{C}-\mathrm{O}$ bond, which lowers the activation energy of the reaction. The role of the phenyl ring in the $\left[\mathrm{C}_{2} \mathrm{OHC}_{2} \mathrm{Phim}\right] \mathrm{Cl}$ ionic liquid appears to be to promote the dehydration process via repulsive hydrophobic interactions between the atoms of the aromatic ring to the chromium(II) ion. Such an interaction is highly reversible, but stabilizes the active catalytic species, preventing deactivation and/or further interactions of the catalyst with HMF that lead to the formation of humins.

Further catalytic upgrading of HMF is required to afford a range of platform chemicals (Fig. 5). HMF is a highly versatile platform chemical used to produce in excess of 175 valuable bio-based derived products, ${ }^{[48]}$ including solvents and fuels, e.g. gamma-valerolactone and 2,5-dimethylfuran, or used to generate biopolymers from monomers including succinic acid and 2,5-furandicarboxylic acid (Fig. 5). In this context ionic liquids, along with other solvents, represent attractive reaction media for hydrogenolysis ${ }^{[38 c, 49]}$ or oxidation ${ }^{[50]}$ steps used in the transformation of HMF. HMF can be also used to obtain hydrocarbons by aldol condensation reactions and used in the synthesis of alkoxymethyl furfural derivatives. ${ }^{[5]}$

\section{Conclusions}

For ionic liquids to be considered as viable reaction media it is imperative that reactions conducted in them are superior to their counterparts conducted in water or organic solvents. ${ }^{[51]}$ Within the context of a biorefinery certain steps could indeed benefit from the application of ionic liq- 


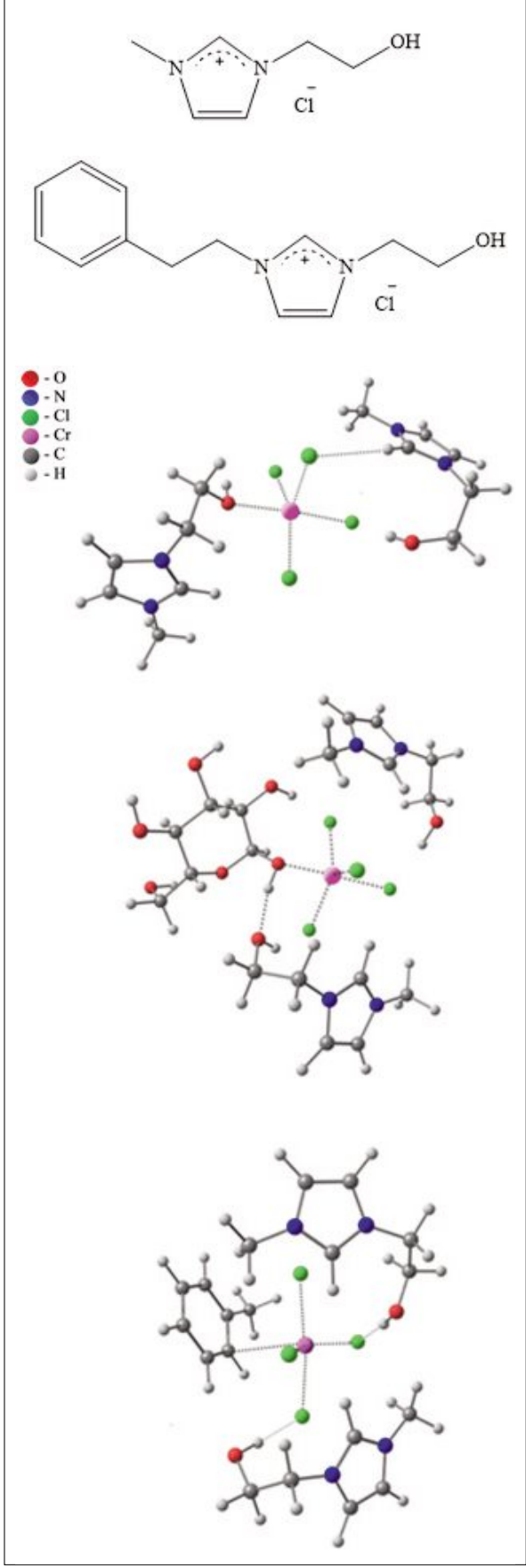

Fig. 4. Ionic liquids used for enhanced $\mathrm{HMF}$ production, i.e. $\left[\mathrm{C}_{2} \mathrm{OHmim}\right] \mathrm{Cl},\left[\mathrm{C}_{2} \mathrm{OHC}_{2}\right.$ Phim] $\mathrm{Cl}$ and computed structures: (top) the $\left[\mathrm{Cr}\left(\mathrm{C}_{2} \mathrm{OHmim}\right) \mathrm{Cl}_{4}\right]\left[\mathrm{C}_{2} \mathrm{OHmim}\right]$ adduct, (center) the $\left[\mathrm{Cr}\left(\mathrm{C}_{2} \mathrm{OHmim}\right) \mathrm{Cl}_{4}\right]\left[\mathrm{C}_{2} \mathrm{OHmim}\right]$ adduct, (bottom) the $\left[\mathrm{Cr}\left(\mathrm{C}_{2} \mathrm{OHmim}\right) \mathrm{Cl}_{4}\right]\left[\mathrm{C}_{2} \mathrm{OHmim}\right]-$ toluene adduct. The arene ring in $\left[\mathrm{C}_{2} \mathrm{OHC}_{2} \mathrm{Phim}\right] \mathrm{Cl}$ stabilizes the catalyst at low substrate concentrations. ${ }^{[47]}$

uids. Ionic liquids not only facilitate recycling and reuse of catalysts and allow facile product extraction, but they may also enhance the product yield and reduce the operating costs. The design of ionic liquids with specific functionalities that have idealized physico-chemical properties for the dissolution and activation of cellulose has recently been demonstrated resulting in a process that appears to be advantageous over other routes. ${ }^{[19]}$

\section{Acknowledgement}

We thank the Swiss National Science Foundation's National Research Programme (NRP 66) for funding our research in this domain.

Received: June 29, 2015

1] K. Sanderson, Nature 2011, 474, S12.

[2] a) P. Gallezot, Chem. Soc. Rev. 2012, 41, 1538; b) J. C. Serrano-Ruiz, R. Luque, A. SepulvedaEscribano, Chem. Soc. Rev. 2011, 40, 5266; c) L. Hu, G. Zhao, W. Hao, X. Tang, Y. Sun, L. Lin, S. Liu, RSC Advances 2012, 2, 11184; d) S. Liu, L. P. Abrahamson, G. M. Scott, Biomass Bioenergy 2012, 39, 1; e) C. O. Tuck, E. Pérez, I. T. Horváth, R. A. Sheldon, M. Poliakoff, Science 2012, 337, 695.

[3] a) M. E. Zakrzewska, E. Bogel-Łukasik, R. Bogel-Łukasik, Chem. Rev. 2010, 111, 397; b) D. M. Alonso, J. Q. Bond, J. A. Dumesic, Green Chem. 2010, 12, 1493; c) N. Yan, C. Zhao, P. J. Dyson, C. Wang, L.-t. Liu, Y. Kou, ChemSusChem 2008, 1, 626.

[4] G. M. Souza, R. Victoria, C. Joly, L. Verdade, 'Bioenergy \& Sustainability: Bridging the gaps', Paris: SCOPE, 2015, pp 139.

[5] M. J. Climent, A. Corma, S. Iborra, Green Chem. 2014, 16, 516.

[6] a) M. Terbojevich, A. Cosani, G. Conio, A. Ciferri, E. Bianchi, Macromolecules 1985, 18, 640; b) C. L. McCormick, T. R. Dawsey, Macromolecules 1990, 23, 3606; c) Y. Nishio, R. S. J. Manley, Macromolecules 1988, 21 , 1270.

[7] K. J. Edgar, K. M. Arnold, W. W. Blount, J. E. Lawniczak, D. W. Lowman, Macromolecules 1995, 28, 4122 .

[8] N. Tamai, D. Tatsumi, T. Matsumoto, Biomacromolecules 2004, 5, 422

[9] a) J.F. Masson, R. S. J. Manley, Macromolecules 1991, 24, 6670; b) J. F. Masson, R. S. J. Manley, Macromolecules 1991, 24, 5914.

[10] D. Loubinoux, S. Chaunis, Text. Res. 1987, 57 , 61.

[11] a) S. Fischer, W. Voigt, K. Fischer, Cellulose 1999, 6, 213; b) K. Hattori, J. A. Cuculo, S. M. Hudson, J. Polym. Sci., Part A: Polym. Chem. 2002, 40,601

[12] a) K. Saalwächter, W. Burchard, P. Klüfers, G. Kettenbach, P. Mayer, D. Klemm, S. Dugarmaa, Macromolecules 2000, 33, 4094; b) K. Saalwächter, W. Burchard, Macromolecules 2001, 34, 5587.

[13] H. P. Fink, P. Weigel, H. J. Purz, J. Ganster, Prog. Polym. Sci. 2001, 26, 1473.
[14] a) H. Qi, C. Chang, L. Zhang, Cellulose 2008, 15, 779; b) L. Weng, L. Zhang, D. Ruan, L. Shi, J. Xu, Langmuir 2004, 20, 2086; c) L. Zhang, D. Ruan, S. Gao, J. Polym. Sci., Part B: Polym. Phys. 2002, 40, 1521.

[15] J. S. Luterbacher, J. M. Rand, D. M. Alonso, J. Han, J. T. Youngquist, C. T. Maravelias, B. F. Pfleger, J. A. Dumesic, Science 2014, 343, 277.

[16] a) L. Deng, J. Li, D.-M. Lai, Y. Fu, Q.-X. Guo, Angew. Chem. Int. Ed. 2009, 48, 6529; b) X.L. Du, L. He, S. Zhao, Y.-M. Liu, Y. Cao, H.-Y He, K.-N. Fan, Angew. Chem. 2011, 123, 7961; c) J. Cui, J. Tan, T. Deng, X. Cui, H. Zheng, Y. Zhu, Y. Li, Green Chem. 2015, 17, 3084; d) J. Deng, Y. Wang, T. Pan, Q. Xu, Q.-X. Guo, Y. Fu, ChemSusChem 2013, 6, 1163; e) J. Tan, J. Cui, T. Deng, X. Cui, G. Ding, Y. Zhu, Y. Li, Chem CatChem 2015, 7, 508 .

17] a) J. S. Luterbacher, J. W. Tester, L. P. Walker, Biotechnol. Bioeng. 2010, 107, 451; b) A. R. C. Morais, A. M. da Costa Lopes, R. BogelŁukasik, Chem. Rev. 2015, 115, 3; c) H. Xie, X. Yu, Y. Yang, Z. K. Zhao, Green Chem. 2014, 16, 2422.

18] a) H. Olivier-Bourbigou, L. Magna, D. Morvan, Appl. Catal. A 2010, 373, 1; b) N. V. Plechkova, K. R. Seddon, Chem. Soc. Rev. 2008, 37, 123; c) L. C. Branco, J. N. Rosa, J. J. Moura Ramos, C. A. M. Afonso, Chem. Eur. J. 2002, 8, 3671

[19] G. Cevasco, C. Chiappe, Green Chem. 2014, 16, 2375.

[20] A. M. Socha, R. Parthasarathi, J. Shi, S. Pattathil, D. Whyte, M. Bergeron, A. George, K. Tran, V. Stavila, S. Venkatachalam, M. G. Hahn, B. A. Simmons, S. Singh, Proc. Natl. Acad. Sci. USA 2014, 111, E3587.

[21] a) P. J. Dyson, Chimia 2005, 59, 66; b) Z. Fei, T. J. Geldbach, D. Zhao, P. J. Dyson, Chem. Eur. J. 2006, 12, 2122.

[22] C. Graenacher, Patent, Vol. 1943176 U.S., 1934.

[23] A. Pinkert, K. N. Marsh, S. Pang, M. P. Staiger, Chem. Rev. 2009, 109, 6712.

[24] R. P. Swatloski, S. K. Spear, J. D. Holbrey, R. D. Rogers, J. Am. Chem. Soc. 2002, 124, 4974.

[25] J. Vitz, T. Erdmenger, C. Haensch, U. S. Schubert, Green Chem. 2009, 11, 417.

[26] R. C. Remsing, R. P. Swatloski, R. D. Rogers, G. Moyna, Chem. Commun. 2006, 1271.

[27] a) A. S. Amarasekara, B. Wiredu, Int. J. Carbohydr. Chem. 2012, 2012, 1; b) C. Li, B. Knierim, C. Manisseri, R. Arora, H. V. Scheller, M. Auer, K. P. Vogel, B. A. Simmons, S. Singh, Bioresour. Technol. 2010, 101, 4900; c) S. Singh, B. A. Simmons, K. P. Vogel, Biotechnol. Bioeng. 2009, 104, 68

[28] Y. Pu, N. Jiang, A. J. Ragauskas, J. Wood Chem. Technol. 2007, 27, 23.

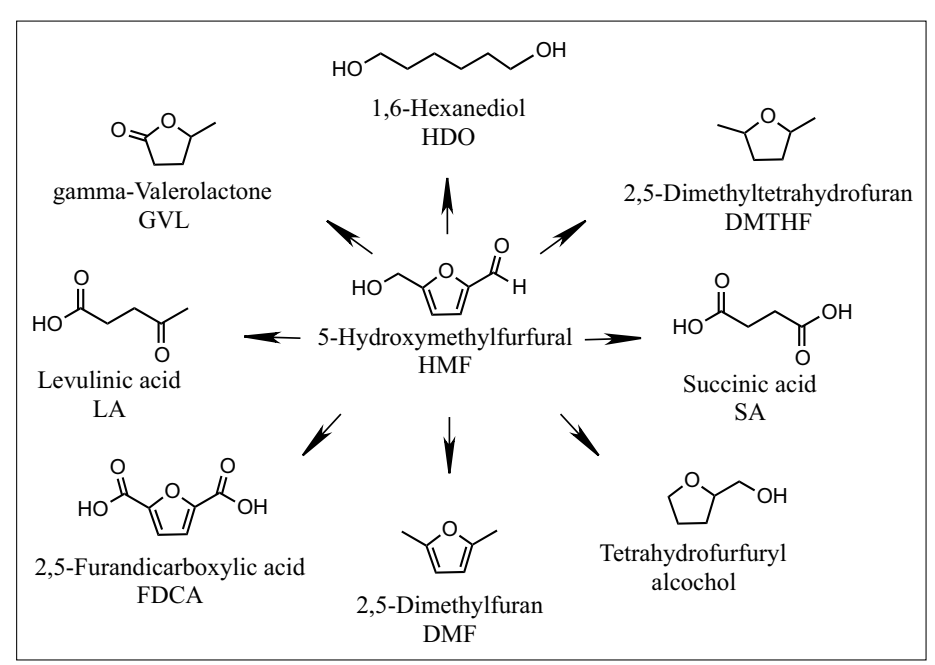

Fig. 5. Examples of valuable platform chemicals that can be obtained from HMF. 
[29] a) P. J. Dyson, Appl. Organomet. Chem. 2002, 16,495 ; b) J. D. Scholten, B. C. Leal, J. Dupont, ACS Catalysis 2012, 2, 184.

[30] a) H. Zhao, C. L. Jones, J. V. Cowins, Green Chem. 2009, 11, 1128; b) A. Xu, J. Wang, H. Wang, Green Chem. 2010, 12, 268.

[31] S. H. Lee, T. V. Doherty, R. J. Linhardt, J. S. Dordick, Biotechnol. Bioeng. 2009, 102, 1368.

[32] a) T. Erdmenger, C. Haensch, R. Hoogenboom, U. S. Schubert, Macromol. Biosci. 2007, 7, 440; b) T. Heinze, K. Schwikal, S. Barthel, Macromol. Biosci. 2005, 5, 520; c) B. R. Caes, T. R. Vanoosbree, F. Lu, J. Ralph, C. T. Maravelias, R. T. Raines, ChemSusChem 2013. 6, 2083.

[33] a) Y. Zhao, X. Liu, J. Wang, S. Zhang, ChemPhysChem 2012, 13, 3126; b) H. Zhao, G. A. Baker, Z. Song, O. Olubajo, T. Crittle, D. Peters, Green Chem. 2008, 10, 696; c) B. Lu, A. $\mathrm{Xu}$, J. Wang, Green Chem. 2014, 16, 1326.

[34] a) M. Zavrel, D. Bross, M. Funke, J. Büchs and A. C. Spiess, Bioresourc. Technol. 2009, 100, 2580; b) Y. Fukaya, K. Hayashi, M. Wada, H. Ohno, Green Chem. 2008, 10, 44.

[35] H. Lateef, S. Grimes, P. Kewcharoenwong, B. Feinberg, J. Chem. Technol. Biotechnol. 2009, $84,1818$.

[36] A. M. da Costa Lopes, R. Bogel-Łukasik, ChemSusChem 2015, 8, 947.

[37] A. Brandt, J. Grasvik, J. P. Hallett, T. Welton, Green Chem. 2013, 15, 550.

[38] a) N. Yan, C. Zhao, P. J. Dyson, C. Wang, L.-t. Liu, Y. Kou, ChemSusChem 2008, 1, 626; b) I.
Delidovich, K. Leonhard, R. Palkovits, Energy Environ. Sci. 2014, 7, 2803; c) Y. Nakagawa, M. Tamura, K. Tomishige, ACS Catalysis 2013, 3, 2655.

[39] a) A. A. Rosatella, S. P. Simeonov, R. F. M. Frade, C. A. M. Afonso, Green Chem. 2011, 13, 754; b) B. R. Caes, M. J. Palte, R. T. Raines, Chem. Science 2013, 4, 196.

[40] a) M. Schwanninger, J. C. Rodrigues, H. Pereira, B. Hinterstoisser, Vib. Spectrosc. 2004, 36, 23; b) R. A. Sheldon, Catal. Today; 2015, 247, 4; c) N. Dimitratos, J. A. Lopez-Sanchez, G. J. Hutchings, Chem. Sci. 2012, 3, 20; d) Y. Yu, H. Wu, AIChE J. 2011, 57, 793; e) H. Wang, G. Gurau, R. D. Rogers, Chem. Soc. Rev. 2012, 41, 1519; f) H. Zhao, J. E. Holladay, H. Brown, Z. C. Zhang, Science 2007, 316, 1597.

[41] a) C. Li, Z. K. Zhao, A. Wang, M. Zheng, T. Zhang, Carbohydr. Res. 2010, 345, 1846; b) M. J. Antal Jr, W. S. L. Mok, G. N. Richards, Carbohydr. Res. 1990, 199, 91; c) R. S. Assary, P. C. Redfern, J. Greeley, L. A. Curtiss, J. Phys. Chem. B 2011, 115, 4341; d) C. Moreau, R. Durand, S. Razigade, J. Duhamet, P. Faugeras, P. Rivalier, P. Ros, G. Avignon, Appl. Catal. A 1996, 145, 211; e) Y.-N. Li, J.-Q. Wang, L.-N. He, Z.-Z. Yang, A.-H. Liu, B. Yu, C.-R. Luan, Green Chem. 2012, 14, 2752.

[42] H. Tadesse, R. Luque, Energy Environ. Sci. 2011, 4, 3913.

[43] X. Yuan, N. Yan, C. Xiao, C. Li, Z. Fei, Z. Cai, Y. Kou, P. J. Dyson, Green Chem. 2010, 12, 228 .
[44] a) N. Yan, X. Yang, Z. Fei, Y. Li, Y. Kou, P. J. Dyson, Organometallics 2009, 28, 937; b) X. Yang, Z. Fei, T. J. Geldbach, A. D. Phillips, C. G. Hartinger, Y. Li, P. J. Dyson, Organometallics 2008, 27, 3971.

[45] N. Yan, Y. Yuan, R. Dykeman, Y. Kou, P. J. Dyson, Angew. Chem. Int. Ed. 2010, 49, 5549.

[46] a) D. Zhao, Z. Fei, T. J. Geldbach, R. Scopelliti, P. J. Dyson, J. Am. Chem. Soc. 2004, 126, 15876; b) Z. Fei, D. Zhao, D. Pieraccini, W. H. Ang, T. J. Geldbach, R. Scopelliti, C. Chiappe, P. J. Dyson, Organometallics 2007, 26, 1588; c) Y. Cui, I. Biondi, M. Chaubey, X. Yang, Z. Fei, R. Scopelliti, C. G. Hartinger, Y. Li, C. Chiappe, P. J. Dyson, Phys. Chem. Chem. Phys. 2010, 12, 1834.

[47] S. Siankevich, Z. Fei, R. Scopelliti, G. Laurenczy, S. Katsyuba, N. Yan, P. J. Dyson, ChemSusChem 2014, 7, 1647.

[48] http://www.ava-co2.com/web/pages/en/ solutions/bio-based-chemistry.php?lang $=E N$.

[49] a) J. Julis, M. Holscher, W. Leitner, Green Chem. 2010, 12, 1634; b) M. Chidambaram, A. T. Bell, Green Chem. 2010, 12, 1253; c) M. G. Al-Shaal, P. J. C. Hausoul, R. Palkovits, Chem. Commun. 2014, 50, 10206.

[50] T. Ståhlberg, E. Eyjólfsdóttir, Y. Y. Gorbanev, I. Sádaba, A. Riisager, Catal. Lett. 2012, 142, 1089.

[51] a) M. Besson, P. Gallezot, Catal. Today 2000, 57, 127; b) T. Mallat, A. Baiker, Chem. Rev. 2004, 104, 3037; c) X. Li, D. Wu, T. Lu, G. Yi, H. Su, Y. Zhang, Angew. Chem. Int. Ed. 2014, 53,4200 . 